\title{
Implementasi Sistem Presensi Menggunakan Biometrik Pada Laboratorium Teknik Informatika Universitas Muhammadiyah Malang
}

\author{
Vindo Widi Tiarno ${ }^{* 1}$, Eko Budi Cahyono ${ }^{2}$, llyas Nuryasin ${ }^{3}$ \\ 1,2,3Teknik Informatika/Universitas Muhammadiyah Malang \\ vindotiarno@gmail.com ${ }^{* 1}$, ebcahyono@yahoo.com², ilyas.umm.ac.id ${ }^{3}$
}

\begin{abstract}
Abstrak
Presensi Laboratorium Teknik Informatika Universitas Muhammadiyah Malang hingga kini masih diatur menggunakan sistem tulis tangan. Aktifitas seperti itu memungkinan kesalahan terhadap pengelolaan data presensi dan tindak kecurangan untuk menduplikat kehadiran. Sistem presensi sidik jari dikelola oleh administrator guna melakukan pendataan terhadap kehadiran praktikan di dalam sistem. Pendataan presensi praktikan dilakukan dengan mendeteksi sidik jari dengan menggunakan mesin pemindai sidik jari. Data presensi dari mesin kemudian dikembangkan lebih lanjut di dalam suatu sistem. Praktikan juga dapat mengakses secara langsung untuk mengetahui status kehadirannya. Presensi praktikan berbasis perangkat lunak menggunakan pemindai sidik jari memiliki kemampuan dapat melihat status dan persentase kehadiran, pendataan peserta praktikum (praktikan, asisten, dan instruktur), jadwal praktikum, dan merekap data. Terutama membantu peserta praktikum dalam mengetahui status kehadirannya pada mata kuliah praktikum yang telah diambil. Dari hasil implementasi diperoleh kesimpulan bahwa secara umum sistem ini dapat membantu memudahkan pihak administrator dalam mengelola data kehadiran peserta praktikum. Sistem ini juga secara umum dapat membantu memudahkan peserta praktikum dalam melihat status kehadirannya.
\end{abstract}

Kata Kunci: Presensi Sidik Jari, Sistem Biometrik

\section{Abstract}

The presence list of the Laboratory of Informatics Engineering University of Muhammadiyah Malang until now still using handwriting system. Such activities may be subject to errors in data management and fraudulent behavior to duplicate the attendance lists. The presence list of fingerprint system is managed by the administrator to collect data on the presence of practicum students in the system. The presence of practicum student data collection is done by detecting fingerprint using fingerprint scanner. Presence data collection from the machine is then further developed in a system. The practicum students also can access directly to know the status of its presence. Presence of software-based praktikan using fingerprint scanner has the ability to see the status and percentage of attendance, data collection practicum participants (student, assistant, instructor), schedule practicum, and data recap. Especially can helping practicum participants in knowing the status of his attendance on the course practicum that has been taken. From the implementation results obtained the conclusion that in general this system can help make it easy the administrator in managing data attendance practicum participants. This system also can generally help facilitate practicum participants in viewing their attendance status.

Keywords: The Presence of Fingerprint, Biometric System

\section{Pendahuluan}

Standar presensi mahasiswa pada Laboratorim Teknik Informatika Universitas Muhammadiyah Malang sejauh ini masih menggunakan sistem tanda tangan di kertas yang memiliki banyak kekurangan, dan hingga kini belum ada perubahan untuk memperbaiki standar presensi tersebut.

Sistem tanda tangan pada kertas ini masih memiliki kelemahan yaitu dapat mempermudah bagi para mahasiswa untuk memalsukan tanda tangan dan lembaran kertas wajib disetorkan ke instansi terkait pemeriksaan kehadiran mahasiswa. Tentunya biaya tambahan juga diperlukan untuk pembelian kertas presensi ini [5]. 
Guna mengatasi masalah tersebut tentu ada solusi yang akan digunakan nantinya. Sebagian besar menerapkan berbagai macam teknologi, salah satunya yaitu penggunaan perangkat untuk mendukung kegiatan agar aktifitas dalam belajar dan mengajar lebih kondusif [2].

Perangkat tersebut berupa perangkat lunak dan perangkat keras yang digunakan untuk menjalankan presensi, namun waktu yang digunakan untuk presensi juga bisa lebih singkat. Perangkat keras tersebut berupa pemindai biometrik pada sidik jari dan perangkat lunak digunakan untuk memonitoring dari hasil pemindai biometrik pada sidik jari [6][7]. Agar evaluasi dan monitoring kehadiran mahasiswa sesuai dengan ketentuan yang berlaku. Perangkat lunak ini juga sangat penting karena data presensi sangat diperlukan. Sangat penting karena data juga digunakan untuk menilai prestasi akademik mahasiswa yakni dengan melihat tingkat kedisiplinan para mahasiswa melalui kehadiran jam masuk serta keluar dari ruang kelas.

Demi mencapai prestasi akademik yang baik bukanlah hal yang mudah dilaksanakan. Ada faktor penting lain untuk mencapai prestasi akademik yang baik yaitu pelaksanaan disiplin dari para mahasiswa, karena hal tersebut merupakan salah satu faktor penentu untuk menunjang keaktifan seorang mahasiswa. Kedisiplinan merupakan kesediaan dan kesadaran untuk tetap menaati semua peraturan dan norma social yang telah berlaku [2].

Dengan adanya perangkat lunak presensi menggunakan sidik jari diharapkan para mahasiswa akan lebih meningkatkan kedisiplinan dalam menggunakan jam pelajaran dengan baik. Dengan kata lain taat pada peraturan yang telah ditetapkan agar semuanya tujuan dapat berjalan dengan lancar dan mahasiswa dapat berprestasi dalam bidang akademik.

\section{Tinjauan Pustaka}

\subsection{Sistem Biometrik}

Pada dasarnya sistem biometrik merupakan metode identifikasi pola yang dilakukan pengidentifikasian secara personal serta melaksanakan otentifikasi dari karekterisasi fisiologis seperti pengidentifikasian sidik jari, telapak tangan, retina, iris, pola mata, struktur wajah dan karakteristik pada perilaku tertentu dimiliki oleh manusia [1]. Secara umum sistem ini dipecah menjadi 2 proses, proses registrasi dan identifikasi. Proses registrasi memiliki fungsi untuk merekam data dari suatu individual dan disimpan menuju sistem. Supaya penggunaan pada proses penyesuaian atau validasi, untuk mendapatkan penyajian secara digital tersebut perlu pemrosesan lanjut agar penyajian cukup untuk mewakili dari sebuah tampilan. Kemudian tampilan ini bisa ditaruh kedalam penyimpanan data untuk sistem biometrik. Proses identifikasi berguna sebagai pengidentifikasian individual pada pengaksesan [5.] Ketika operasional perpindahan biometrik menangkap keunikan saat diidentifikasi dan diubah kedalam bentuk digital, setelah itu oleh fitur ekstraksi akan melewati proses menjadi representasi yang tidak berbeda dengan tampilan dan setelah itu disinkronkan untuk memperoleh id [7].

Karekteristik fisiologis dari suatu individu bisa digunakan sebagai tanda pengenal atau tanda pengenal perseorangan, didalam suatu karekteristik fisiologis suatu individu agar bisa dikatakan biometrik tentu ada persyaratan dari salah satu karakteristik yaitu, unik, kekal, dan dapat dihitung berdasarkan jumlahnya dan dinilai, dari perhitungan itu dapat dimanfaatkan untuk kegiatan pengidentifikasian. Dari sebagian karekteristik fisiologis untuk pengenalan secara individu yang pernah dilakukan ataupun dalam pengidentifikasian atau pengembangan selanjutnya diantaranya adalah sidik jari, wajah, retina, iris mata, pola telapak tangan, karakteristik suara dan tanda tangan [1].

\subsection{Parameter Biometrik}

Biometrik merajuk kepada pengidentifikasian manusia atas dasar karakteristika atau keunikan yang dipunyai oleh individu itu sendiri. Didalam ilmu komputerisasi biometrik berguna sebagai wujud pengidentifikasian dan kontrol akses [4]. Bermacam-macam perspektif fisiologi yang dimiliki manusia bisa berguna untuk otentifikasi pada biometrik. Ditemukan sebagian pengukuran yang bisa berguna untuk memberi nilai keselarasan dari karakteristik yang telah dimanfaatkan untuk otentikasi secara biometrik [1]. Pengukuran tersebut yaitu antaranya:

1. Uniqueness.

Setiap individu harus memiliki sifat yang tidak akan sama antara individu satu dengan lainnya dalam sebuah populasi.

2. Universality.

Setiap manusia sudah pasti mempunyai sifat tersebut.

REPOSITOR, Vol. 2, No. 1, Januari 2020: 27-34 
3. Collectability

Memudahkan dalam mengukur dari sifat setiap individu agar mudah digunakan.

4. Permanence

Secara umum sifat manusia terjadi begitu alami. Namun harus tetap terukur sebaik mungkin, awet untuk melewati jaman dan aktifitas lainnya untuk masa yang akan datang.

5. Performance

Berkaitan dengan keakuratan, respon dan daya tahan teknologi yang akan digunakan.

6. Acceptability

Ada kaitan dengan dapat diterimanya oleh masyarakat dari teknologi yang digunakan, sehingga karakter biometrik siap dipergunakan oleh mereka.

7. Circumvention

Ada kaitannya dengan tidak sulitnya suatu sifat yang mungkin dapat direplikakan atau dibuat tiruannya dengan cara tertentu [1].

\subsection{Teknologi Biometrik}

Dari hasil penelitian ditemukan berbagai jenis biometrik yang telah membuat adanya suatu alternatif yang dapat diterapkan oleh suatu organisasi. Sebagian dari teknologi biometrik yang ada dapat menunjukkan berbagai macam penggunaan, kelebihan yang dimiliki oleh biometrik dapat di terapkan salah satunya pada sistem keamanan namun beberapa kendala perlu diperhatikan untuk setiap teknologi yang dikeluarkan [8].

Salah satunya yang perlu diperhatikan ialah cara penyajian berbagai jenis teknologi biometrik keamanan tersebut, bukan mengenai pemilihan teknologi biometrik paling baik. Akan tetapi lebih cenderung kepada bagaimana pemilihan subtansi terhadap biometrik keamanan yang sesuai dengan substansi tersebut. Penerapan teknologi biometrik keamanan yang terapkan pada suatu substansi tidak menjadi jaminan dapat mengendalikan hal sama dengan substansi lain.

\subsection{Model Interaksi Sensor Biometrik}

Model interaksi sensor biometrik menggambarkan bagaimana metrik yang diukur dari sensor biometrik (kualitas sampel dan kinerja sistem) dapat dikaitkan dengan ergonomi (fisik dan kognitif) dan kegunaan (efektivitas, efisiensi dan kepuasan) metrik untuk mengevaluasi kinerja keseluruhan dari sistem biometrik [9].

Menerapkan model ini memungkinkan gambaran yang lebih lengkap untuk lebih memahami apa yang mempengaruhi kinerja sistem biometrik. Selama sembilan tahun terakhir, tim awal Kukula dan Elliot mengembangkan salah satu model pertama yang menghubungkan kegunaan dan biometrik. Model memiliki asal-usulnya terletak di persimpangan kegunaan, faktor manusia, dan kualitas gambar atau kinerja. Sebagai contoh, pekerjaan awal dari tim membahas masalah penempatan tangan, berdasarkan bukti yang dikumpulkan selama studi kelayakan biometrik. Model pertama ini dibuat pada tahun 2005 didasarkan pada penelitian sebelumnya di bidang interaksi manusia atau perangkat biometrik. dan diperbarui secara berkala dan secara bertahap serangkaian metrik kegunaannya sudah ditetapkan [10].

\subsection{Identifikasi Sidik Jari}

Kompleks adalah sifat dari sidik jari. Menjabarkan karakteristik untuk difungsikan, lembaga penegak hukum telah banyak menetapkannya, untuk mengidentifikasi dan menguraikan sidik jari. Menganalisa sidik jari tentu menggunakan proses algoritma digital, metodologi yang digunakan tentu saja ada yang sama selama beberapa tahun di dalam lapangan penegakan hukum.

Biometrik memiliki sistem untuk mengotentikasi pemakai dengan cara perbandingan dari pola-pola dan punggung bukit pada sidik jari. Untuk mematahkan anggapan tersebut, perangkat lunak menjadi pembeda dari area punggung bukit, global feature, dan local feature [3].

\subsection{Pengenalan Pola Pemindaian Sidik Jari}

Pengenalan pola pemindaian pola sidik jari sepertii pada Gambar 1 dibagi menjadi beberapa, yaitu sebagai berikut:

1. Imaging sidik jari akan disalin kedalam format numerik dengan cara system capturing kemudian bisa diproses oleh komputer.

2. Noice yang dimiliki image sidik jari, dihilangkan (preprocessing).

3. Image sidik jari yang telah dibersihkan noicenya, dilanjutkan proses pembineran yaitu 0 dan 1 . 
4. Proses selanjutnya adalah pengidentifikasian atau pengenalan pola sidik jari.

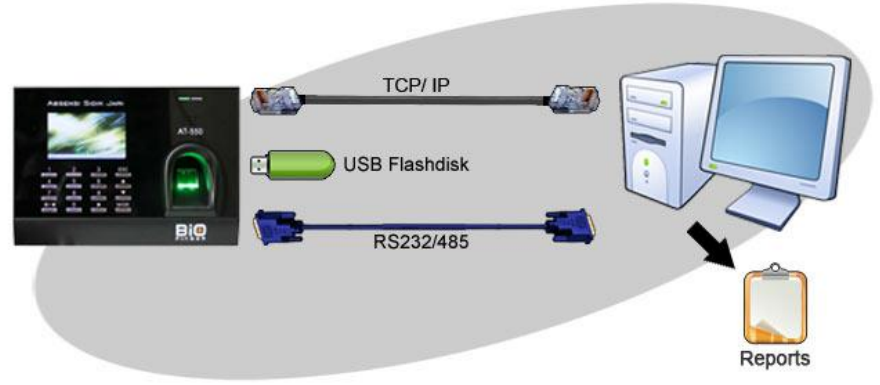

Gambar 1. Skema Pengenalan Mesin Sidik Jari

\subsection{Arsitektur Sistem}

Secara umum sistem presensi praktikan dengan memanfaatkan sidik jari seperti pada Gambar 2 dibagi menjadi dua bagian umum sebagai berikut:

1. Sistem untuk registarasi atau pendaftaran yang digunakan untuk menyimpan data sidik jari anggota (instruktur, asisten dan praktikan).

2. Sistem untuk indentifikasi berguna untuk mengidentifikan pola sidik jari yang lebih mendekati diantara sidik jari input dengan sidik jari yang terdapat pada basis data.

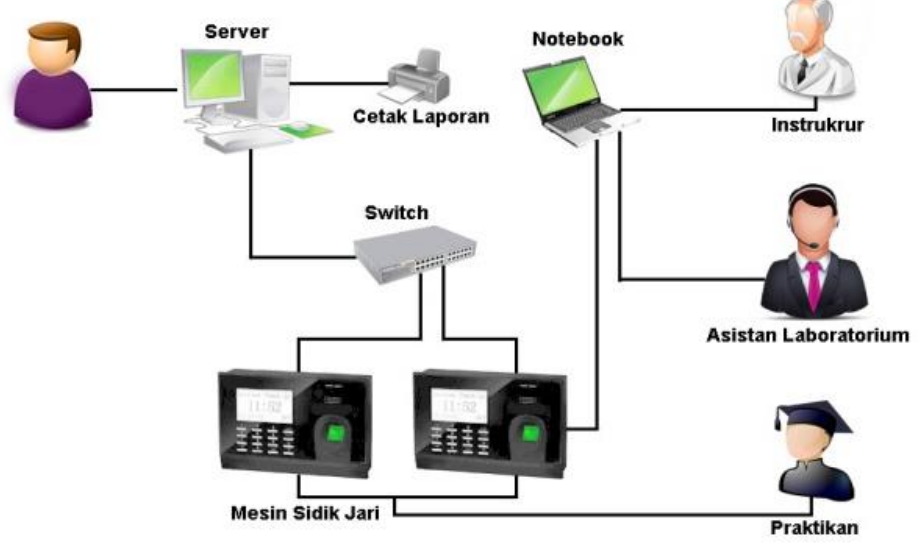

Gambar 2. Arsitektur Sistem Pada Presensi Sidik Jari

\section{Hasil Penelitian Dan Pembahasan}

Pada dasarnya perancangan sistem yang dibuat mengenai perancangan software. Maksudnya software tersebut adalah aplikasi berbasis database digunakan sebagai penyimpanan data, sehingga data yang dimasukan digunakan untuk mengakses daftar hadir atau presensi dengan menggunakan biofinger scanning, dimana sidik jari digunakan sebagai kode akses atau sebagai validasi yang kemudian akan diterima oleh database. Komputer digunakan sebagai penerima input yang berisikan sebuah aplikasi database, dan driver machine digunakan sebagai pemroses kode sidik jari sebagai output.

Program yang telah diisikan kedalam driver machine diaktifkan melalui program visualisasi, masukan dari program visual adalah berupa kode sidik jari. Setelah kode sidik jari dibaca oleh aplikasi tersebut sesuai database yang ada, maka sistem akan memerintahkan ke driver mesin sehingga mesin biofinger scanning akan mengidentifikasi apakah kode sidik jari sudah sesuai dengan data yang sudah ada. Bagian ini akan di awali dengan tinjauan permasalahan yang ada fokus kepada gambaran umum sistem presensi yang akan dibuat, diharapkan sistem ini dapat di program dan di implementasi.

\subsection{Kebutuhan Sistem}

Studi kebutuhan sistem adalah tinjauan sekilas yang ada pada faktor utama sesuai kebutuhan. Kebutuhan sistem berguna untuk mengidentifikasi apakah teknologi yang ada nantinya dapat digunakan pada sistem. Karena itu kebutuhan harus diperhatikan dari sistem yang mencangkup beberapa hal, yaitu sebagai berikut:

REPOSITOR, Vol. 2, No. 1, Januari 2020: 27-34 
1. Kebutuhan fungsional

a. Alur dasar presensi sidik jari :

- User atau pengguna melakukan scanning sidik jari.

- Data user akan diproses oleh sistem setelah scanning sidik jari.

- Jika data valid sistem langsung memproses data user dan langsung melakukan pengecekan, jika data tidak valid maka user dapat melakukan penginputan ulang sampai data valid.

- Data user yang masuk dikelola oleh admin.

- Pembuatan laporan data presensi dilakukan oleh admin.

b. Kasus lain (apabila user belum mendaftar)

- User dapat konfimasi kepada admin.

- User melakukan pendaftaran kepada admin (sidik jari, nip/nim, nama, alamat, nomor kontak, dan lain-lain)

- Admin mengelola data diri user ke sistem tersebut.

- Selesai

2. Kebutuhan Non Fungsional

- Presensi dilakukan sesuai jadwal praktikum, paling lambat 20 menit, jika presensi dilakukan melebihi dari 20 menit melalui data akan dilakukan tindak lanjut, seperti dinyatakan absen atau tidak hadir.

- Penginputan sidik jari apabila tidak valid akan terdapat notifikasi dari mesin sidik jari, dan dapat dilakukan berulang-ulang hingga sidik jari dapat diproses oleh sistem.

- Scanning atau penginputan sidik jari berdurasi minimal selama 2 detik.

Scanning atau penginputan sidik jari menggunakan bagian jari yang pertama kali didaftarkan ke dalam sistem. Namun juga terdapat sidik jari dari jari yang berbeda untuk cadangan bila sidik jari pertama mengalami masalah.

\subsection{Identifikasi Masalah}

Pada sistem presensi Laboratorium Teknik Infomartika Muhammadiyah Malang yang ada saat ini masih mengandalkan presensi dalam bentuk lembar kertas dan presensi jenis ini sering mengalami berbagai macam kendala (Gambar 3), sehingga ada berbagai macam kemungkinan yang akan terjadi terhadap lembar kertas yang digunakan untuk presensi. Agar sistem presensi laboratorium dapat berjalan sesuai kehendak, maka diperlukan sistem pencatatan kehadiran yang valid dilihat dari sisi autentifikasi dan batasan waktu penginputan kehadiran tersebut.

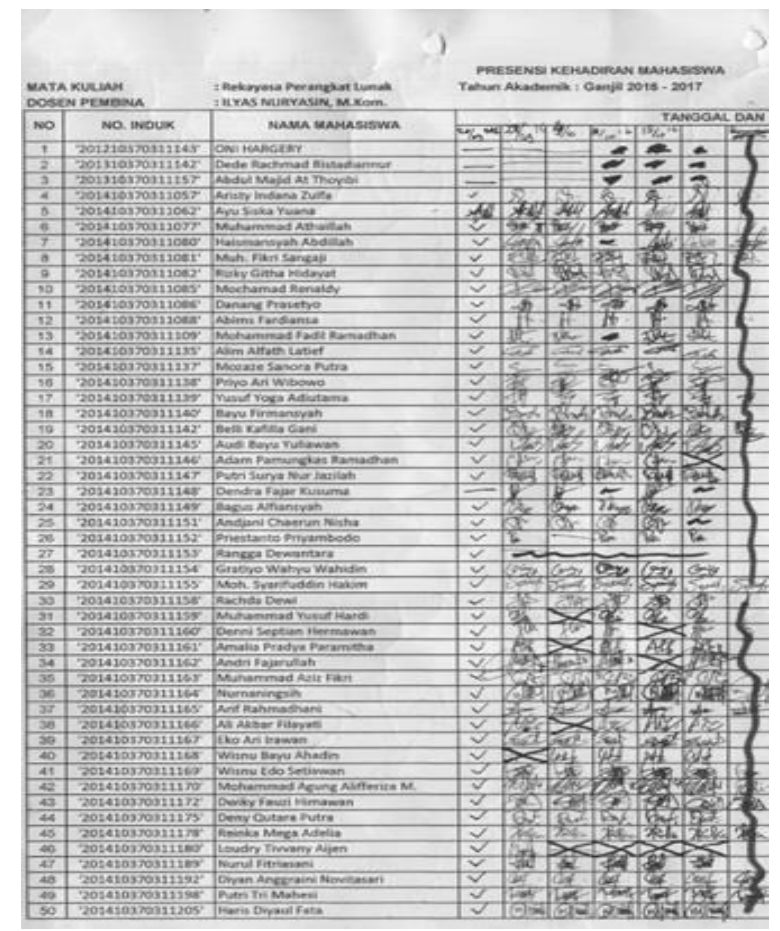

Gambar 3. Contoh Presensi Tulis Tangan 


\subsection{Gambaran Umum Data}

Pada sistem presensi Laboratorium Teknik Informatika Muhammadiyah Malang ini di identifikasikan ada 3 (tiga) macam kebutuhan data yaitu:

1. Melakukan Registrasi

Bagi anggota yang belum mempunyai akses atau belum terdaftar untuk sebagai anggota, maka harus melakukan registrasi pada pihak administrator dengan memberikan biodata, yaitu nip/nim, nama, nomor telepon, alamat, dan melakukan input sidik jari sebanyak dua kali tahap yang digunakan sebagai verifikasi kode akses anggota.

2. Melakukan Masukan (Input) Validasi Sidik Jari

Sebelum melakukan presensi biometrik anggota harus sudah terintegrasi dengan sistem. Sistem tersebut akan melakukan pencocokan atau validasi sidik jari, sebagai kode akses yang akan diverifikasi oleh aplikasi database untuk dapat mengakses kehadiran (presensi).

3. Memperbarui dan Menghapus Data

Bagi administrator dapat memperbarui, menambah atau bahkan menghapus data yang ada di dalam data sistem sesuai dengan kebutuhan.

\subsection{Gambaran Umum Fungsi}

Pada system keamanan ruang kelas ini ada 3 (tiga) fungsi yang dibutuhkan yaitu :

1. Fungsi Data

Pada tingkat ini basis data mempunyai fungsi untuk menyimpan data anggota. Sehingga data dapat dikontrol melalui komputer untuk keperluan keamanan, jika terjadi hal yang tidak sesuai dengan ketentuan dari laboratorium.

2. Fungsi Administrator

Pada tingkat ini administrator dapat melakukan registrasi atau menghapus data anggota dan dapat melihat laporan jadwal praktikum sesuai dengan kebutuhan. Administrator juga dapat melakukan akses kedalam sistem presensi secara langsung atau melakukan verifikasi sidik jari anggota, dengan melakukan login terlebih dahulu.

3. Fungsi Anggota (Instruktur, Asisten, dan Praktikan)

Pada tingkat ini sebagai anggota hanya dapat melakukan akses kedalam sistem prensensi dengan melakukan login terlebih dahulu.

\subsection{Diagram Use Case Presensi Biometrik}

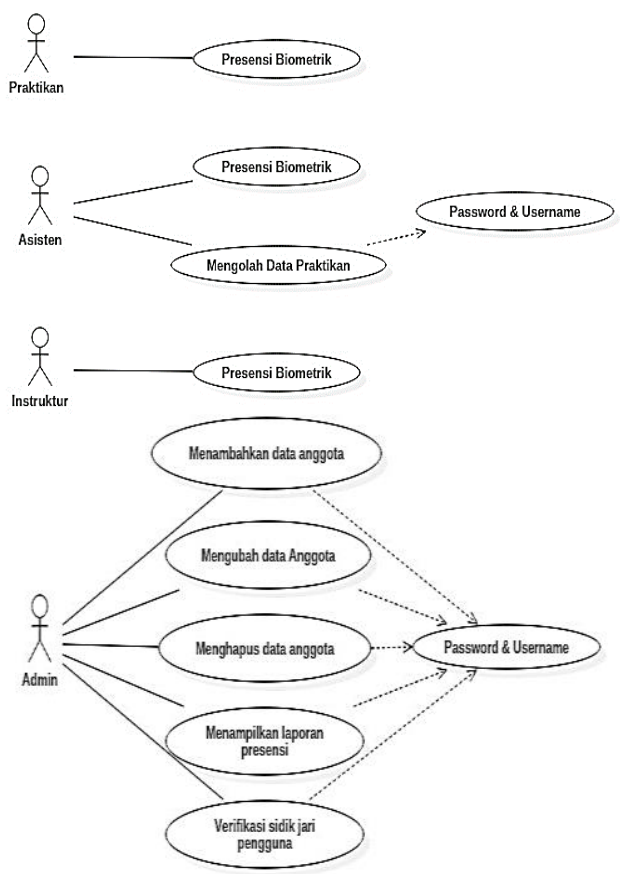

Gambar 4. Diagram Use Case Administrator dan User

REPOSITOR, Vol. 2, No. 1, Januari 2020: 27-34 
Gambar 4 Diagram Use Case merupakan sebuah aktor administrator dan anggota pada sistem presensi biometik.

Adanya Diagram Use Case sangat memudahkan untuk menyusun requirement dari sebuah sistem, dengan cara komunikasikan rancangan dengan user dan merancang test case untuk semua fitur yang sudah ada di sistem. Gambaran aktifitas beberapa atau jumlah seluruh aktor, use case, dan interaksi diantara komponen-komponen tersebut yang memperkenalkan suatu sistem yang akan dibangun semua itu merupakan sebuah diagram use case. Diagram Use Case memberi penjelasan tentang manfaat suatu sistem jika dilihat menurut pandangan orang yang berada diluar sistem.

\section{Kesimpulan}

Dari hasil pengimplementasian dan analisa dari Sistem Presensi Menggunakan Biometrik Pada Laboratorium Teknik Informatika Universitas Muhammadiyah dapat disimpulkan bahwa sistem ini:

1. Implementasi sistem presensi menggunakan biometrik ini telah berhasil diimplementasikan.

2. Sistem presensi menggunakan biometrik ini membantu peserta praktikum dalam mengetahui status kehadirannya pada mata kuliah praktikum yang telah diambil.

3. Sistem presensi menggunakan biometrik ini membantu peserta praktikum dalam mengetahui persentase kehadirannya pada mata kuliah praktikum yang telah diambil.

4. Sistem presensi menggunakan biometrik ini membantu pihak administrator dalam pengolahan data peserta praktikum dan perhitungan persentase sebagai laporan akhir presensi.

5. Sistem presensi menggunakan biometrik mudah digunakan untuk semua peserta praktikum dan administrator.

\section{Referensi}

[1] A. C. Lomte, "Biometric fingerprint authentication with minutiae using ridge feature extraction," 2015 Int. Conf. Pervasive Comput. Adv. Commun. Technol. Appl. Soc. ICPC 2015, vol. 0, no. c, 2015.

[2] A. Fakih, I. K. Raharjana, and B. Zaman, "Pemanfaatan Teknologi Fingerprint Authentication untuk Otomatisasi Presensi Perkuliahan," J. Inf. Syst. Eng. Bus. Intell., vol. 1, no. 2, pp. $41-$ 48, 2015.

[3] Dani, Trimada. (2000). Buku Petunjuk Teknis Polri di Bidang Identifikasi (Jilid 2). Jakarta: Departemen Pertahanan Markas Besar Kepolisian Negara Republik Indonesia.

[4] M. Bellaaj, R. Boukhris, A. Damak, and D. Sellami, "based Multimodal Biometric Recognition System," pp. 1-8, 2016.

[5] M. Sabir, "Aiding biometric system based on fingerprint enhancement and matching," pp. 19, 2016.

[6] S. Nasional et al., "Perancangan Otentikasi Sidik Jari Pada Biometric Payment Design Of Authentication Fingerprint For Biometric Payment," vol. 2016, no. Sentika, pp. 18-19, 2016.

[7] S. Presensi et al., "Sistem Presensi Dengan Metode Sidik Jari Menggunakan Sensor Fingerprint Dengan Tampilan Pada Pc," J. Saintia Fis., vol. 1, no. 1, pp. 1-11, 2013.

[8] Taringan. Josua., "Biometric Security: Alternatif Pengendalian Dalam Sistem Informasi Akuntansi Terkomputerisasi," vol. 2016, no. pp. 1-16, 2016.

[9] A. Omotosho, O. Adegbola, B. Adelakin and A. Adelakun, "Exploiting Multimodal Biometrics in E-Privacy Scheme for Electronic Health Records," Journal of Biology, Agriculture and Healthcare, vol. 4, no. 18, pp. 22-33, 2014.

[10] S. J. Elliott, K. O'Connor, E. Bartlow, J. J. Robertson, and R. M. Guest, "Expanding the human-biometric sensor interaction model to identity claim scenarios," 2015 IEEE Int. Conf. Identity, Secur. Behav. Anal. ISBA 2015, no. March, 2015. 
REPOSITOR, Vol. 2, No. 1, Januari 2020: 27-34 